\title{
Earlier smoking after waking and the risk of asthma: a cross-sectional study using NHANES data
}

\author{
Arielle S. Selya ${ }^{1 *} \mathbb{D}$, Sunita Thapa ${ }^{1,2}$ and Gaurav Mehta ${ }^{1}$
}

\begin{abstract}
Background: Recent research shows that nicotine dependence conveys additional health risks above and beyond smoking behavior. The current study examines whether smoking within 5 min of waking, an indicator of nicotine dependence, is independently associated with asthma outcomes.

Methods: Data were drawn from five pooled cross-sectional waves (2005-14) of NHANES, and the final sample consisted of $N=4081$ current adult smokers. Weighted logistic regressions were run examining the relationship between smoking within 5 min of waking and outcomes of lifetime asthma, past-year asthma, and having had an asthma attack in the past year. Control variables included demographics, smoking behavior, family history of asthma, depression, obesity, and secondhand smoking exposure.

Results: After adjusting for smoking behavior, smoking within 5 min was associated with an approximately 50\% increase in the odds of lifetime asthma ( $O R=1.46, p=.008$ ) and past-year asthma ( $O R=1.47, p=.024)$, respectively. After additionally adjusting for demographics and other asthma risk factors, smoking within 5 min of waking was associated with a four-fold increase in the odds of lifetime asthma ( $O R=4.05, p=.015)$.

Conclusions: Smoking within 5 min of waking, an indicator of nicotine dependence, is associated with a significantly increased risk of lifetime asthma in smokers. These findings could be utilized in refining risk assessment of asthma among smokers.
\end{abstract}

Keywords: Asthma, Cigarettes, Nicotine dependence, Smoking, Time to first cigarette

\section{Background}

Asthma is a highly disabling but treatable disease, which consists of chronic airway inflammation and episodes of acute exacerbations in response to certain stimuli. Several risk factors for asthma have been identified, and a notable avoidable risk factor is cigarette smoking [1]. However, most existing research does not distinguish between nicotine dependence (ND), a psychological construct capturing the addiction to nicotine, and smoking behavior. Traditionally, smoking behavior and ND were largely considered synonymous; however, recent research has increasingly highlighted the importance of distinguishing between them. ND is a psychological

\footnotetext{
* Correspondence: arielle.selya@med.und.edu

${ }^{1}$ Master of Public Health Program, Department of Population Health, University of North Dakota, 1301 North Columbia Rd. Stop 9037, Grand Forks, ND 58202, USA

Full list of author information is available at the end of the article
}

construct capturing addiction to smoking, and this is to some extent separable from smoking behavior itself. For example, adolescent smokers often develop ND at low, even non-daily levels of smoking [2-4], and this predicts future smoking behavior even after accounting for prior smoking behavior $[3,5,6]$, while other demographic groups show very low ND despite heavy smoking behavior [2]. Moreover, ND poses a higher risk than does smoking behavior alone for several other smoking-related health outcomes, including lung cancer [7, 8], larynx cancer [9], head and neck cancer [10], and chronic obstructive pulmonary disease (COPD) [11, 12]. A limited number of studies reported that asthma significantly increases the risk of both smoking behavior and ND [13, 14]; however, the association between asthma and ND was not assessed independently of smoking behavior. Thus, very little is

(c) The Author(s). 2018 Open Access This article is distributed under the terms of the Creative Commons Attribution 4.0 International License (http://creativecommons.org/licenses/by/4.0/), which permits unrestricted use, distribution, and reproduction in any medium, provided you give appropriate credit to the original author(s) and the source, provide a link to the Creative Commons license, and indicate if changes were made. The Creative Commons Public Domain Dedication waiver (http://creativecommons.org/publicdomain/zero/1.0/) applies to the data made available in this article, unless otherwise stated. 
known about whether higher ND is associated with increased risk of asthma, over and above smoking behavior.

The current study tests the novel hypothesis that smoking within $5 \mathrm{~min}$ of waking, a version of time to first cigarette (TTFC) which is a strong and reliable indicator of ND $[15,16]$, is associated with a greater risk of asthma even after accounting for lifetime smoking history. Data are pooled across five consecutive, cross-sectional waves (2005-06, 2007-08, 2009-10, 2011-12, and 2013-14) of the National Health and $\mathrm{Nu}-$ trition Examination Survey (NHANES) survey, and include current adult smokers. Though causality cannot be established here, data were restricted to those who initiated smoking prior to developing asthma, in order to ensure a temporal relationship that is at least consistent with smoking as a causal factor in the development or exacerbation of asthma. The relationships between smoking within 5 min after waking and binary outcomes of 1) lifetime asthma, 2) past-year asthma, and 3) having had an asthma attack in the past year were examined using weighted logistic regressions. Control variables included smoking behavior (past-month cigarettes per day (CPD) and years of smoking duration), demographic characteristics (age, race/ethnicity, and gender), and other risk factors for asthma (obesity, family history of asthma, depression, and secondhand smoke exposure).

\section{Methods}

\section{Study sample}

This study utilized data from five cross-sectional waves (2005-06, 2007-08, 2009-10, 2011-12, and 2013-14) of NHANES, a publicly available, nationally-representative survey conducted by the Centers for Disease Control. NHANES is a nationally representative sample of the non-institutionalized civilian U.S. population that is conducted on an ongoing, semiannual basis since 1999. NHANES consists of an extensive questionnaire on medical conditions, health-related behaviors and risk factors, and a subcomponent involving physical examination and laboratory tests. Since complete smoking behavior and ND information was available only from current smokers 20 years or older, participants younger than 20 or who did not report being a current smoker were excluded from all analyses. Additionally, among participants who reported having had asthma at some point in their lifetime, those who developed asthma prior to initiating smoking were also excluded. The final analytic sample includes $N=4081$ current adult smokers.

\section{Measures}

Asthma outcomes were examined with three binary variables: self-reported lifetime asthma ("Has a doctor or other health professional ever told you that you have asthma?"); and among those who said yes, self-reported past-year asthma ("Do you still have asthma?"), and having reported at least one asthma attack in the past year ("During the past 12 months, have you had an episode of asthma or an asthma attack?"). Additionally, self-reported age of asthma diagnosis ("How old were you when first told you had asthma?") was used to determine exclusion from the final study sample: participants were excluded if age of asthma diagnosis was younger than the self-reported age of first regular smoking.

Smoking within 5 min after waking was derived from self-reported time to first cigarette (TTFC), perhaps the best single-item measure of ND $[15,16]$, which was asked using the question "How soon after waking up do you smoke?" In order to ensure sufficient group sizes in the current sample, the four original response categories were dichotomized into $\leq 5$ (high dependence) vs. > 5 min (low to moderate dependence), consistent with other recent research [17].

Control variables included current smoking behavior (self-reported cigarettes per day (CPD) in the past 30 days) and lifetime smoking behavior (years of smoking duration, calculated by subtracting self-reported age of first regular smoking from age at questionnaire), in accordance with recent recommendations for controlling for smoking behavior [18] .

Additionally, demographic characteristics included age, sex, and race/ethnicity. Race/ethnicity was self-reported as "non-Hispanic white," "non-Hispanic black," "Mexican-American," "other Hispanic," and "other;" for the current analyses, "Mexican-American" and "other Hispanic" were combined into a single category, and participants reporting "other" were excluded from analyses due to small sample size $(N=220)$.

Other risk factors for asthma were used as potential confounding variables, and included self-reported family history of asthma, depression (derived from 10 items based on the DSM-5 criteria), obesity (measured in the physical examination component of NHANES), and secondhand smoke exposure (SHS; dichotomized into any vs. no self-reported exposure to cigarette smoke at home and in the workplace).

\section{Statistical analysis}

Weighted logistic regression was used in accordance with NHANES Analytic Guidelines [19] using R statistical software and its "survey" package to examine outcomes of lifetime asthma, past-year asthma, and having had an asthma attack in the past year. Weighted regressions take into account NHANES' complex sampling design to produce results that are representative of the larger U.S. noninstitutionalized civilian population, rather than the particular NHANES sample. The outcomes were each examined as a function of smoking within 5 min after waking. For each outcome, three models of 
varying complexity were run: 1) an unadjusted model; 2) a model adjusted for smoking behavior (past-month CPD and years of smoking duration); and 3) a model additionally adjusted for other risk factors for asthma (family history of asthma, depression, obesity), demographic characteristics (age, race/ethnicity, and sex), and interactions of TTFC with a) secondhand smoke exposure [20, 21] and b) sex [22]. Missing data on variables were handled by listwise deletion.

\section{Results}

Table 1 shows descriptive statistics separately for those who smoke within 5 min of waking $(N=1290)$ and those who smoke after $5 \mathrm{~min}$ of waking $(N=2791)$. Those who reported smoking within 5 min of waking were approximately 1.5 times as likely to report having asthma at some time in their lives, 1.5 times as likely to report still having asthma in the past year, and 1.7 times as likely to report having had an asthma attack in the past year. Additionally, those who smoked within 5 min after waking reported heavier past-month smoking, and a longer lifetime smoking duration.

Weighted regression analyses of varying complexity are presented in Table 2. At the unadjusted level, smoking within $5 \mathrm{~min}$ of waking was associated with higher odds of lifetime and past-year asthma, as well as of a past-year asthma attack. When adjusting for current and lifetime smoking behavior, smoking within 5 min of waking was associated with an approximately $47 \%$ increase in the odds of lifetime asthma, and a $46 \%$ increase in the odds of past-years asthma. Finally, when also adjusting for demographic characteristics and other risk factors for asthma, smoking within 5 min of waking remained independently associated with lifetime asthma, such that those who smoke within $5 \mathrm{~min}$ of waking have approximately four times the odds of reporting lifetime asthma. Secondhand smoke exposure significantly moderated this relationship, such that SHS exposure slightly weakened the effect of smoking within 5 min after waking. Finally, there was a trend between smoking within 5 min of waking with both past-year asthma and having had an asthma attack in the past year. Unweighted regressions are presented in Additional file 1: Table S1.

Significant interactions were also found between smoking within $5 \mathrm{~min}$ of waking and secondhand smoke exposure in the fully-adjusted model for both lifetime and past-year asthma (Table 2). This indicates significant moderation, such that the odds of asthma for those with both risk factors (smoking within 5 min of waking and being exposed to second hand smoke) are lower than would be expected based on their respective independent OR's. Similarly, an additional interaction between smoking within 5 min of waking and sex was found only for outcomes of past-year asthma, such that being male and smoking within $5 \mathrm{~min}$ of waking results in a higher risk of past-year asthma than would be expected by the respective independent OR's of these variables.

Table 1 Descriptive statistics of sample

\begin{tabular}{|c|c|c|c|}
\hline Measure & Smoking within 5 min of waking $(N=1290)$ & Smoking after 5 min of waking $(N=2791)$ & p \\
\hline Lifetime asthma & $150,11.6 \%$ & $210,7.5 \%$ & $<.001$ \\
\hline Past-year asthma & $115,9.0 \%$ & $153,5.5 \%$ & $<.001$ \\
\hline Past-year asthma attack & $60,4.8 \%$ & $82,3.0 \%$ & .006 \\
\hline Cigarettes per day & $20.0,1.0-25.0$ & $10,6.0-20.0$ & $<.001$ \\
\hline Smoking duration & $29.5,18.0-40.0$ & $28,15.0-40.0$ & .001 \\
\hline Age & $46.0,35.0-56.0$ & $46.0,33.0-59.0$ & .969 \\
\hline Sex & & & .753 \\
\hline Female & $561,43.5 \%$ & $1230,44.1 \%$ & \\
\hline Male & $729,56.5 \%$ & $1561,55.9 \%$ & \\
\hline Race & & & $<.001$ \\
\hline White & $812,63.0 \%$ & $1541,55.2 \%$ & \\
\hline Black & $352,27.3 \%$ & $698,25.1 \%$ & \\
\hline Hispanic & $126,9.8 \%$ & $552,19.8 \%$ & \\
\hline Depression & $261,23.5 \%$ & $388,16.0 \%$ & $<.001$ \\
\hline Obesity & $371,30.4 \%$ & $817,30.8 \%$ & .843 \\
\hline Family history of asthma & $324,25.8 \%$ & $575,21.1 \%$ & .001 \\
\hline Secondhand smoking & $895,92.8 \%$ & $1460,75.9 \%$ & $<.001$ \\
\hline
\end{tabular}

Categorical variables are presented as $N$, valid percentage, and continuous variables are presented as median, interquartile range. $p$-values are based on chisquare tests for categorical variables, and Wilcoxon signed-rank tests for continuous variables. Bold: $p<.05$ 
Table 2 Weighted regression results of smoking within 5 min of waking on asthma outcomes

\begin{tabular}{|c|c|c|c|c|}
\hline \multirow[t]{3}{*}{ Model } & \multirow[t]{3}{*}{ Covariate } & \multicolumn{3}{|l|}{ Outcome } \\
\hline & & Lifetime Asthma & Past-Year Asthma & Past-Year Asthma Attack \\
\hline & & $\begin{array}{l}\text { OR }(95 \% \mathrm{Cl}) \\
p \text {-value }\end{array}$ & $\begin{array}{l}\text { OR }(95 \% \mathrm{Cl}) \\
p \text {-value }\end{array}$ & $\begin{array}{l}\text { OR }(95 \% \mathrm{Cl}) \\
p \text { value }\end{array}$ \\
\hline Unadjusted & Smoking within 5 min. (vs. > 5 min.) & $\begin{array}{l}1.71(1.26-2.31) \\
p=.001\end{array}$ & $\begin{array}{l}1.72(1.22-2.43) \\
p=.003\end{array}$ & $\begin{array}{l}1.66(1.04-2.67) \\
p=.038\end{array}$ \\
\hline Adjusted for smoking behavior ${ }^{a}$ & Smoking within 5 min. (vs. > 5 min.) & $\begin{array}{l}1.47(1.11-1.93) \\
p=.008\end{array}$ & $\begin{array}{l}1.46(1.06-2.01) \\
p=.024\end{array}$ & $\begin{array}{l}1.31(0.82-2.09) \\
p=.268\end{array}$ \\
\hline \multirow[t]{3}{*}{ Adjusted for smoking ${ }^{a}$ and other covariates ${ }^{b}$} & Smoking within 5 min. (vs. > 5 min.) & $\begin{array}{l}4.05(1.35-12.14) \\
p=.015\end{array}$ & $\begin{array}{l}3.95(0.93-16.84) \\
p=.069\end{array}$ & $\begin{array}{l}5.45(0.85-34.88) \\
p=.079\end{array}$ \\
\hline & Smoking within $5 \mathrm{~min} \times \mathrm{SHS}$ & $\begin{array}{l}0.23(0.08-0.71) \\
p=.014\end{array}$ & $\begin{array}{l}0.20(0.04-0.90) \\
p=.041\end{array}$ & $\begin{array}{l}0.18(0.02-1.31) \\
p=.096\end{array}$ \\
\hline & Smoking within $5 \mathrm{~min} \times \mathrm{sex}$ & - & $\begin{array}{l}3.21(1.56-6.64) \\
p=.003\end{array}$ & - \\
\hline
\end{tabular}

Results are presented as odds ratio (95\% confidence interval), $p$-value. Boldface indicates statistical significance $(p<.05)$

a Smoking covariates: cigarettes per day and years of smoking duration

${ }^{b}$ Other covariates: depression, obesity, family history of asthma, secondhand smoke exposure (SHS), age, sex, race/ethnicity, and interactions of smoking within

5 min with secondhand smoke exposure and sex. Interaction terms are only included in the model if $p<.10$

\section{Discussion}

This study presents the novel finding that smoking sooner after waking, a reliable indicator for ND, is independently associated with a heightened risk of lifetime and recent asthma outcomes among a nationally representative sample of current adult smokers, over and above current and lifetime smoking behavior. Notably, the association with lifetime asthma remained significant after also adjusting for demographic characteristics and other risk factors for asthma, such that those who smoke within $5 \mathrm{~min}$ of waking are at an approximately four-fold risk of reporting asthma at some point in their lives.

The relationships between smoking within $5 \mathrm{~min}$ of waking with outcomes of past-year asthma and past-year asthma attacks were not significant after adjusting for current and lifetime smoking behavior, demographics, and other risk factors for asthma. Considering that active smoking has been shown to aggravate inflammation and hypersensitivity of the airways [23], we had expected to find that smoking within 5 min of waking to be associated with past-year asthma outcomes as well. However, the relationship did show a trend $(p<.10)$, which suggests that this negative finding may reflect low statistical power due to a relatively small analytic sample given the complexity of the fully-adjusted model. This possibility is bolstered by the fact that smoking within 5 min was associated with both past-year asthma and past-year asthma attacks at the bivariate level, and with past-year asthma after adjusting only for current and lifetime smoking behavior. Future studies using larger sample sizes and/or prospective data are needed to more rigorously evaluate whether indicators of ND are associated with concurrent asthma outcomes and the exacerbation of asthma symptoms.
It is noteworthy that the strength of the relationship between smoking within 5 min and asthma was stronger after adjusting for covariates, relative to the unadjusted model and the model adjusted only for smoking behavior. Including the interaction terms of smoking within 5 min with secondhand smoke exposure and with sex were critical in explaining this increase; excluding these significant interactions resulted in substantially lower and even nonsignificant OR's (data not shown). The significance of these interaction terms indicate important moderation of the relationship between time to first cigarette in the morning and asthma. In the case of sex, the current findings align with sex difference in the relationship between ND and asthma [22]; though differences in the statistical models prevent a direct comparison with the current findings. In the case of secondhand smoke exposure, this confirms previous research showing that those exposed to secondhand smoke have more severe ND [20, 21]. Taken together with the current findings, this suggests ND as a possible mechanism for why secondhand smoke exposure increases the risk of asthma. Future research is needed to disentangle the complex relationship between secondhand smoke exposure, ND, and asthma, including ND as a possible mediator.

Two potential explanations may underlie the current findings that smoking within $5 \mathrm{~min}$ of waking is associated with a heightened four-fold risk of asthma. Asthma involves inflammation and hypersensitivity of airways which could be a result of persistent irritation by the components of cigarette smoke [23]. Given that smokers can moderate their nicotine intake by altering their smoking style [24, 25], more dependent smokers may inhale more deeply and take more puffs per cigarette [26, 27]. If dependent smokers (as indicated by smoking 
within 5 min of waking) routinely extract more nicotine, and incidentally more smoke and tars from each cigarette, this may raise the risk of increased inflammatory mediators and bronchiolar damage. This could explain the significantly higher risk of lifetime asthma among such smokers. In this explanation, the effect of ND on asthma would be fully mediated through nuanced smoking style rather than the number of cigarettes consumed.

A second potential explanation could be that the relationship between ND and asthma may be the result of a common genetic predisposition. Genetic pathways have been identified that increase the risk of both ND and COPD [28, 29] as well as ND and lung cancer [30-32]. Though no such common genetic risk is currently known for ND and asthma, independent genetic risk factors have been identified for both ND [33-36] and asthma [37-39]. Future genetic studies examining potential common genetic links are warranted to test this potential explanation.

\section{Strengths and limitations}

Strengths of this study include its novelty in establishing an association between smoking within 5 min of waking, a symptom of ND, and lifetime asthma. Additionally, the use of data from the large, nationally-representative NHANES survey increase the generalizability of our findings to current adult smokers in the US. The current study extends the existing literature in important ways by demonstrating a novel link between smoking within 5 min of waking, an indicator of ND, and asthma outcomes.

Limitations of the current study should be taken into account. First, due to the use of cross-sectional data, temporality and causation cannot be examined. This is especially important considering that asthma often develops in children who have not yet initiated smoking; however, the current study reduced this limitation by excluding participants whose asthma preceded smoking initiation. Second, the results are limited to the accuracy of self-reported variables. It is possible that some diagnoses of asthma are other types of pulmonary disorders such as chronic obstructive pulmonary disease, bronchitis, etc. However, the wording of the question ("have you ever been told by a doctor or health professional...") reduces the likelihood of an incorrect diagnoses. Nevertheless, follow-up research is necessary to replicate these findings using clinical diagnosis rather than self-report. Third, the measurement of ND in NHANES is restricted to a single question (i.e. TTFC) to current smokers; this prevents an examination of ND among ex-smokers or passive smokers and excludes other aspects of the multi-dimensional construct of ND. Finally, the current study is intended as a preliminary examination of a novel association, and future research is needed to more rigorously test the relationship between ND and asthma outcomes.

\section{Conclusions}

The current preliminary findings report a novel association between smoking within $5 \mathrm{~min}$ of waking, an indicator of ND, and lifetime occurrence of asthma. That is, among smokers with similar smoking histories, those who are more "addicted" as indicated by sooner smoking after waking have an approximately four-fold risk of having asthma at some time in their lives, independently of smoking behavior and other risk factors for asthma. This novel finding has important potential implications for treating smokers suffering from asthma. In particular, if the current preliminary findings are corroborated and extended in future research, healthcare professionals could screen smokers based on how soon they smoke after waking in order to more accurately assess their risk for asthma, among other health outcomes. Through more detailed risk assessment of smokers, closer monitoring and increased support for smoking cessation for those at risk for asthma, we could ultimately reduce the disease burden associated with asthma.

\section{Additional file}

Additional file 1: Table S1. Unweighted regression results of smoking within 5 min of waking on asthma outcomes. (DOCX 16 kb)

\section{Abbreviations}

COPD: Chronic Obstructive Pulmonary Disease; CPD: Cigarettes per Day; IDeA: Institutional Development Award; ND: Nicotine Dependence; NHANES: National Health and Nutrition Examination Survey; OR: Odds Ratio; SHS: Second Hand Smoke; TTFC: Time to First Cigarette

\section{Funding}

This work was supported by an Institutional Development Award (IDeA) from the National Institute of General Medical Sciences of the National Institutes of Health under grant number P20GM103442 to Dr. Donald Sens, Department of Pathology, School of Medicine \& Health Sciences at the University of North Dakota, Grand Forks, ND. The funding agency was not involved in the design of the study, data collection, analysis, interpretation, or writing of this manuscript.

\section{Availability of data and materials}

The datasets analyzed during the current study are publicly available in the National Health Nutrition Survey (NHANES), https://www.cdc.gov/nchs/ nhanes/index.htm

\section{Authors' contributions}

AS, ST and GM performed data analysis and drafted the manuscript. AS conceived and designed the study, supervised the data analysis, interpreted the data, and drafted parts of the manuscript. All authors contributed to manuscript revisions and approved the final version of this article.

\section{Ethics approval and consent to participate}

This study was performed in accordance with the Declaration of Helsinki and was approved by the University of North Dakota IRB under IRB-201407-036. Consent to participate is not applicable for this study, because this is publicly available, existing data. 


\section{Consent for publication}

Not applicable.

\section{Competing interests}

The authors declare that they have no competing interests.

\section{Publisher's Note}

Springer Nature remains neutral with regard to jurisdictional claims in published maps and institutional affiliations.

\section{Author details}

${ }^{1}$ Master of Public Health Program, Department of Population Health, University of North Dakota, 1301 North Columbia Rd. Stop 9037, Grand Forks, ND 58202, USA. ²Department of Public Policy, Vanderbilt University School of Medicine, 2525 West End Ave, Suite 1200, Nashville, TN 37203, USA

\section{Received: 2 April 2018 Accepted: 13 June 2018}

\section{Published online: 18 June 2018}

\section{References}

1. Siroux V, Pin I, Oryszczyn MP, Le Moual N, Kauffmann F. Relationships of active smoking to asthma and asthma severity in the EGEA study. Epidemiological study on the genetics and environment of asthma. Eur Respir J. 2000;15(3):470-7.

2. Kandel DB, Chen K. Extent of smoking and nicotine dependence in the United States: 1991-1993. Nicotine Tob Res. 2000;2(3):263-74.

3. Difranza JR, Savageau JA, Rigotti NA, Fletcher K, Ockene JK, McNeill AD, Coleman M, Wood C. Development of symptoms of tobacco dependence in youths: 30 month follow up data from the DANDY study. Tob Control. 2002;11(3):228-35.

4. O'Loughlin J, DiFranza J, Tyndale RF, Meshefedjian G, McMillan-Davey E, Clarke PB, Hanley J, Paradis G. Nicotine-dependence symptoms are associated with smoking frequency in adolescents. Am J Prev Med. 2003; 25(3):219-25.

5. Dierker L, Hedeker D, Rose J, Selya A, Mermelstein R. Early emerging nicotine dependence symptoms in adolescence predict daily smoking in young adulthood. Drug Alcohol Depend. 2015;151:267-71.

6. Dierker L, Mermelstein R. Early emerging nicotine-dependence symptoms: a signal of propensity for chronic smoking behavior in adolescents. J Pediatr. 2010;156(5):818-22.

7. Muscat JE, Ahn K, Richie JP Jr, Stellman SD. Nicotine dependence phenotype and lung cancer risk. Cancer. 2011;117(23):5370-6.

8. Kunze U, Scholer E, Schoberberger R, Dittrich C, Aigner K, Bolcskei P, Groman E. Lung cancer risk measured by the Fagerstrom test for nicotine dependence? Nicotine Tob Res. 2007:9(5):625-6.

9. Muscat JE, Liu HP, Livelsberger C, Richie JP Jr, Stellman SD. The nicotine dependence phenotype, time to first cigarette, and larynx cancer risk. Cancer Causes Control. 2012;23(3):497-503.

10. Muscat JE, Ahn K, Richie JP Jr, Stellman SD. Nicotine dependence phenotype, time to first cigarette, and risk of head and neck cancer. Cancer. 2011;117(23):5377-82.

11. Guertin KA, Gu F, Wacholder S, Freedman ND, Panagiotou OA, ReyesGuzman C, Caporaso NE. Time to first morning cigarette and risk of chronic obstructive pulmonary disease: smokers in the PLCO Cancer screening trial. PLoS One. 2015;10(5):e0125973.

12. Selya AS, Oancea SC, Thapa S. Time to first cigarette, a proxy of nicotine dependence, increases the risk of pulmonary impairment, independently of current and lifetime smoking behavior. Nicotine Tob Res. 2016;18(6):1431-9.

13. McLeish AC, Cougle JR, Zvolensky MJ. Asthma and cigarette smoking in a representative sample of adults. J Health Psychol. 2011;16(4):643-52.

14. Van De Ven MO, van Zundert RM, Engels RC. Effects of asthma on nicotine dependence development and smoking cessation attempts in adolescence. Asthma. 2013;50(3):250-9.

15. Fagerstrom K. Time to first cigarette; the best single indicator of tobacco dependence? Monaldi Arch Chest Dis. 2003;59(1):91-4

16. Transdisciplinary Tobacco Use Research Center (TTURC) Tobacco Dependence Phenotype Workgroup, Baker TB, Piper ME, DE MC, Bolt DM, Smith SS, Kim SY, Colby S, Conti D, Giovino GA, et al. Time to first cigarette in the morning as an index of ability to quit smoking: implications for nicotine dependence. Nicotine Tob Res. 2007;9(Suppl 4):S555-70.
17. Khaled SM, Bulloch AG, Williams JV, Lavorato DH, Patten SB. Major depression is a risk factor for shorter time to first cigarette irrespective of the number of cigarettes smoked per day: evidence from a National Population Health Survey. Nicotine Tob Res. 2011;13(11):1059-67.

18. Peto J. That the effects of smoking should be measured in pack-years: misconceptions 4. Br J Cancer. 2012;107(3):406-7.

19. Mirel LB, Mohadjer LK, Dohrmann SM, Clark J, Burt VL, Johnson CL, Curtin LR. National Health and nutrition examination survey: estimation procedures. Vital Health Stat 2. 2007-2010:2013(159):1-17.

20. Okoli $\subset$, Browning S, Rayens MK, Hahn EJ. Secondhand tobacco smoke exposure, nicotine dependence, and smoking cessation. Public Health Nurs. 2008;25(1):46-56.

21. Okoli CT, Kodet J. A systematic review of secondhand tobacco smoke exposure and smoking behaviors: smoking status, susceptibility, initiation, dependence, and cessation. Addict Behav. 2015:47:22-32.

22. Guo SE, Ratner PA, Okoli CT, Johnson JL. The gender-specific association between asthma and the need to smoke tobacco. Heart Lung. 2014;43(1):77-83.

23. Stapleton M, Howard-Thompson A, George C, Hoover RM, Self TH. Smoking and asthma. J Am Board Fam Med. 2011;24(3):313-22.

24. Kassel JD, Greenstein JE, Evatt DP, Wardle MC, Yates MC, Veilleux JC, Eissenberg T. Smoking topography in response to denicotinized and high-yield nicotine cigarettes in adolescent smokers. J Adolesc Health. 2007:40(1):54-60.

25. Veilleux JC, Kassel JD, Heinz AJ, Braun A, Wardle MC, Greenstein J, Evatt DP, Conrad M. Predictors and sequelae of smoking topography over the course of a single cigarette in adolescent light smokers. J Adolesc Health. 2011; 48(2):176-81.

26. Jiménez-Ruiz CA, Miravitlles M, Sobradillo V, Gabriel R, Viejo JL, Masa JF, Fernández-Fau L, Villasante C. Can cumulative tobacco consumption, FTND score, and carbon monoxide concentration in expired air be predictors of chronic obstructive pulmonary disease? Nicotine Tob Res. 2004;6(4):649-53.

27. Kim DK, Hersh CP, Washko GR, Hokanson JE, Lynch DA, Newell JD, Murphy $J R$, Crapo JD, Silverman EK. Epidemiology, radiology, and genetics of nicotine dependence in COPD. Respir Res. 2011:12(1):9.

28. Galvan A, Dragani TA. Nicotine dependence may link the $15 \mathrm{q} 25$ locus to lung cancer risk. Carcinog. 2010;31(3):331-3.

29. Kaur-Knudsen D, Nordestgaard BG, Bojesen SE. CHRNA3 genotype, nicotine dependence, lung function and disease in the general population. Eur Respir J. 2012;40(6):1538-44.

30. MacQueen DA, Heckman BW, Blank MD, Van Rensburg KJ, Park JY, Drobes DJ, Evans DE. Variation in the a 5 nicotinic acetylcholine receptor subunit gene predicts cigarette smoking intensity as a function of nicotine content. Pharmacogenomics J. 2014;14(1):70-6.

31. Strasser AA, Benowitz NL, Pinto AG, Tang KZ, Hecht SS, Carmella SG, Tyndale RF, Lerman CE. Nicotine metabolite ratio predicts smoking topography and carcinogen biomarker level. Cancer Epidemiol Biomark Prev. 2011:20(2):234-8.

32. Strasser AA, Malaiyandi V, Hoffmann E, Tyndale RF, Lerman C. An association of CYP2A6 genotype and smoking topography. Nicotine Tob Res. 2007;9(4): $511-8$.

33. Bierut L, Stitzel J, Wang J, Hinrichs A, Grucza R, Xuei X, Saccone N, Saccone $S$, Bertelsen $S$, Fox L, et al. Variants in nicotinic receptors and risk for nicotine dependence. Am J Psychiatry. 2008;165(9):1163-71.

34. Yang J, Wang S, Yang Z, Hodgkinson CA, larikova P, Ma JZ, Payne TJ, Goldman D, Li MD. The contribution of rare and common variants in 30 genes to risk nicotine dependence. Mol Psychiatry. 2014;20(11):1467-78.

35. Bidwell LC, McGeary JE, Gray JC, Palmer RHC, Knopik VS, MacKillop J. NCAM1TTC12-ANKK1-DRD2 variants and smoking motives as intermediate phenotypes for nicotine dependence. Psychopharmacol. 2015;232(7):1177-86.

36. Haberstick BC, Timberlake D, Ehringer MA, Lessem JM, Hopfer CJ, Smolen A Hewitt JK. Genes, time to first cigarette and nicotine dependence in a general population sample of young adults. Addiction. 2007;102(4):655-65.

37. Postma DS, Bleecker ER, Amelung PJ, Holroyd KJ, Xu J, Panhuysen CIM, Meyers DA, Levitt RC. Genetic susceptibility to asthma - bronchial Hyperresponsiveness Coinherited with a major gene for atopy. N Engl J Med. 1995;333(14):894-900.

38. Zhang Y, Moffatt MF, Cookson WOC. Genetic and genomic approaches to asthma: new insights for the origins. Curr Opin Pulm Med. 2012;18(1):6-13.

39. Wan YI, Shrine NRG, Soler Artigas M, Wain LV, Blakey JD, Moffatt MF, Bush A Chung KF, Cookson WOCM, Strachan DP, et al. Genome-wide association study to identify genetic determinants of severe asthma. Thorax. 2012;67(9): $762-8$. 